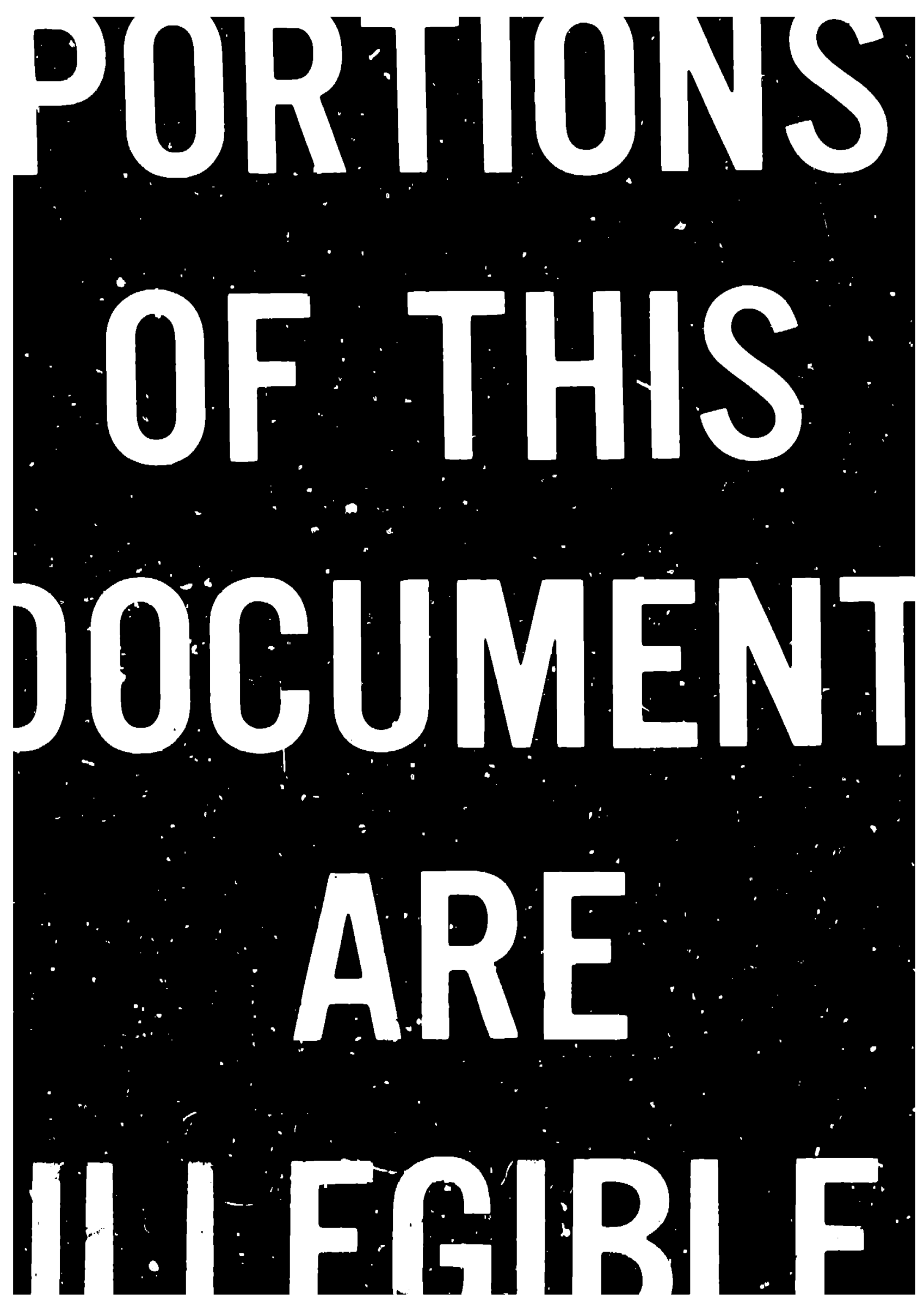


LA-UR $-82-1867$

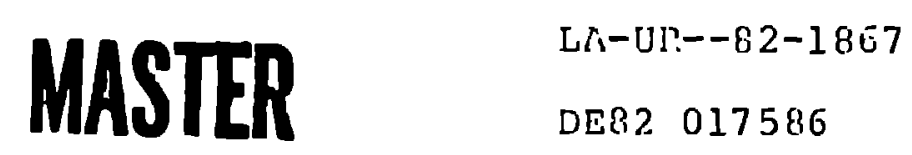

$10 N F-8.21013--2$

Los Alamos National Laboratory is oparated by ine Univoralty of CLlifornia for the Unilec Stalea Deparnment of Enargy under contract W.7405-ENG-36.

TITLE: BONDED STACKED-RING INSULATOR FOR THE ANTARES ELECTRON GUN

AUthliR(G): D. Stine, G. R. Allen, E. Eaton and B. Weinstein

submitted to: Conference on Electrical Insulation and i)lelectric Phenomena, Amherst, MA, October 1982

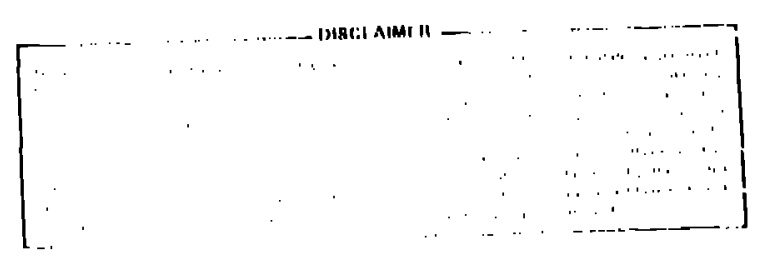

By ecceptence of this eflicle, the nublisher recognizes thet the U.S Ooverninent retains e nonexclusive, royaliy-free licenee lo publiten oi reproduce the published form of Itils contribulion, of 10 allow others 10 do so. for U.S. Governmeri" durposes

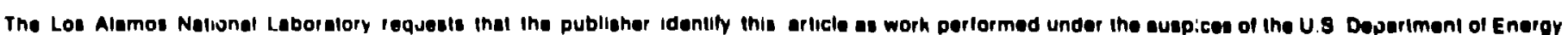

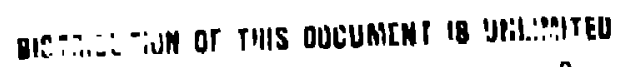

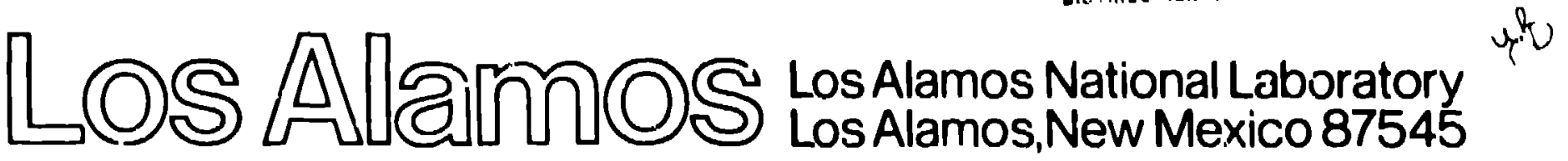




\title{
BONDED STACKED-RING INSULATOR FOR THE ANTARES ELECTRON GUN
}

R. D. Stine, G. R. Allen, E. Eaton, and $B$. We inste in

\author{
Los Aiamos National Laboratory \\ P. 0. Box 1663 \\ -os Aiamos, New Mexico 87545
}

\begin{abstract}
INTRODUCTION
Antares is a high energy $\mathrm{CO}_{2}$ laser under construction at the Los Alamos National Laboratory as part of tre Inertial Confinament Fusion Program.

The electrical discharge in the laser gas is controlled by a low-current-ciensity, large-area electror beam. The beam is produced by a cold-cathode, grid-controlled electron gun (Fig. 1) operating at voltages up to 500 $k$ ilovolts (kV). The coaxtal cathode/grid assembly is $7.7 \mathrm{~m}$ long and weighs approximately $3000 \mathrm{~kg}$. This assembly is supported at each end by bonded stack-ring insulators. The insulator between the cathode and grid is 81 cm dianeter and $25 \mathrm{~cm}$ lony, inade up of six bonded sections; the unit between the grid and anode is the saine diameter but 48 centimeters long and made up of 12 bonded sections. Both of these insulators are shown in Fig. 2. Between the two bushings is the grid connection ring. The insulator construction consists of $3.2 \mathrm{~cm}$ thict: epoxy rings, bonded to $.6 \mathrm{~cm}$ thick aluminum rings (Fig. 3). This bonded construction eliminates the multiple "o" rings and tie rods which are frequently used in high voltage insulators and also simplifies the support of the grid/cathode assembly in the electron gun shell (Fig. 4). Transformer oil fllls the interlor of the insulator, whlle the outside of the insulator has a $10^{-7}$ torr vacuum environment.
\end{abstract}


We have fabricated two complete sets of insulators for two Antares electron guns. One set has been installed in an electron gun which has been fired over 2000 times at voltages from $350 \mathrm{kV}$ to $500 \mathrm{kV}$. In the following sections we describe the mechanical and electrical design and the fabrication techniques for these insulaturs.

\section{MECHANICAL DESIGN}

The insulators support a weight of $2950 \mathrm{~kg}(6,500$ lbs.) resulting in bending stresses of .09MPa (100 psi) a.7d shear stresses of .34MPa (50 psi) in the bond joints. In addition, there is an unknown shock load caused by the discharge.

In an effort to find the best material for the insulating rings, three impact and thre? tensile specimens were made of each of fourte en different formulaticns. The impact strengths ranged from .23 to $.76 \mathrm{~J} / \mathrm{cm}(.43$ to 1.43 foot-lbs./in.). The selected formulation consisted of Epon 828. Armstrong fiexibilizer and DEA. No filler material wa's used. The mechical properties of this material are $.73 \mathrm{~J} / \mathrm{cm}$ (1.37 foct-1bs./in.) impact strength and $75.6 \mathrm{MPa}(10,959 \mathrm{psi})$ tensile strength. The material was cured at $75^{\circ} \mathrm{C}$ for 16 hours. Additional samples were given a postcure of $140^{\circ} \mathrm{C}$ for 6 hours, and these averaged $.76 \mathrm{~J} / \mathrm{cm}(1.42$ foot-lbs./in.) and $80.0 \mathrm{MPa}$ $(11,602$ psi).

Having selected the material, efforts were focused on developing a workable fabrication technique. The rinis were cast in thin fiberglass molds and machined to size. After initlally experiencing significant breakage during machining, the residual stress pattern of the rings was examined using polarlzed light. Slow cooling of the rings over a 16 hour period resulted in a much improved residual stress pattern. In additiun, fixture was developed that held each ring with uniform pressure around the inside diameter during the machining operation. Us-ing Cimrool as a lubricant, a cut of $3 \mathrm{~mm}(.12 \mathrm{in.})$ and a feed of $25 \mu \mathrm{m}(.010 \mathrm{in.})$ reduced the breakage of these slowly couled rings to about 5 percent. 


\section{BONDING OPERATION}

The bonding operation was performed in four basic steps:

(1) surface preparation, (2) application of adhesive, (3) fixturing, and (4) cleanup. A fixture which heid the epoxy and aluminum rings concentric within the prescribed tolerance of 0.030 " was designed and fabric ated. It also provided contact pressure of $\sim 12$ psi during the epoxy adhesive cure.

Surface preparation of the aluminum rings prior to adhesive bonding consisted of: (1) vapor degreasing, (2) bead blasting with glass beacis at 80 psi pressure, and (3) acid etching for 10-15 minutes in chromic-sulfuric acid at $150^{\circ} \mathrm{F}$ followed by a water rinse and drying. The epoxy rings already had roughened surfaces from mach ining and were cleaned by solvent wiping with acetone.

The epoxy adhesive formulation was Epon 828 cured with Versamid 140 in a $1: 1$ ratio by weight. This formulation was chosen because of past experfence regarding its adhesion to aluminum/epoxy, ics reliability, viscosity, pot life, and the fact that it cures at room temperature within 24 hours. Adhesive was applied to both the aluminum and epoxy ring surfaces with a brush, the rings were assembled, and uniform pressure was applied to the joints by calibrated springs in the fixture. Corsiderable squeeze-out of adhesive orcurred imediately after pressure was applied and cont inuea for some time. Cleanup was started immediately on both the inside and outside surfares of the stack. Acetone-damp rags we $A E$ used, with care taken not to saturate the still-wet adhesive bond lines with solvent.

It should be noted that a maxiumum of four epoxy and four aluminum rings were bonded at any one time in the fixture. This allowed rompletion of all the bonding operations with in the pot life of the adhestve.

Ultimate stack height is controlled to some extent by careful measurment of all individual components prior to assembly. Bond line thickness aspears to be less 
than 0.001 " on each ring surface, but an accurate determination has not been made because of dimensional variations in the components. Final stack height and paralielism was achieved by bonding the stack slightly over-height and then machining the top insulatirig ring prior to bonding the top flange.

\section{ELECTRICAL DESIGN}

The Antares electron gun must withstand approximately $3 \cap 0 \mathrm{kV}$ between the cathode and grid for the first few hundred nanoseconds until the cathode blades begin to emit. Once the gun begins to draw current, the grid voltage rises to within a few tens of kilovolts $n$ - ir. cathode voltage. Thus, the majority of the gur: appears between the grid and anode during the 5-11, pulse width (across insulators 1 and $4, \mathrm{Fig}$. 1). The cathede voltage wave shape (Fig. 5), shows the initial voltage spike when blade ignition occurrs, the rise to peak and the chop of the tail when the voltage is diverted.

As is common with many other high-voliage vacuum devices (accelerators, $x$-ray tubes, etc.), the weakest link per unit length in voltage holdoff strength is surface flashover of the vacium insulators. To achieve a maximum safety factor in flashover strength, as well as provide a simple mechanical configuration, a stackedring bonded insulator design was chosen.

The primary factors affecting the surface flashover of a stasked-ring vacuum insulator are tine puise shape (risetime and width), the insuiator material, the thickness of the insulator rings and he angle that the dielectric makes with the field [1], [2], [3]. The pulse parameters were fixed by gun prirformance requirements. The other variables were established by tradeoffs between surface flashover, mechanical strength and fabrication r.onsiderations.

Mechanical and fabrication aspects suggest that a minimum angle should be used to give a maximum bond joint width for a given choser insulator width, and that a maximum insulator thickness is desired to give a minimu'm number of 'sonding operations. 
The insulation material has been shown to have a flashover voltage of $-225 \mathrm{kV}$ across a $1.27 \mathrm{~cm}$ sample with an angle hetween the field and insulator surface of $45^{\circ}$ and a pulse risetime of 5 us [3]. The broad maxima of flashover voltage as a function of angle for various insulating materials, as given by Milton, indicate tinat the flashover voltage for epoxy at $35^{\circ}$ should not be significantly different from that obtained at $45^{\circ}$. Also, in is data indicates that the flashover field for a constant angle varies as the inverse square root of the insulator thickness.

With the above constraints and data poinis in mind, an initial design was se?ected which had an insulation thickness of $3.2 \mathrm{~cm}$ and an angle of $35^{\circ}$.

io obtain an approximation of the insulator material vacuum flashover characteristics under pulsed conditions, a series of tests on small erjxy ring camples was conducted. In all cases the angle on the vac um side of the test specimen was mairitained at $35^{\circ}$. Three sample thicknesses were tested: $1.27 \mathrm{~cm}, 1.9 \mathrm{~cm}$, and $3.175 \mathrm{~cm}$. The applied voltage had a riset ime of approximately 100 ris and a 6 us RC decay. The voltage was raised in small steps to assure that the flashover always occurred on the pulse decay. The vacuum surface flashover voltage and zverage field for the three sample thicknesses is shown in Fig. 6 .

Static field plots of the final stacked-ring insulator configuration were made to determine the worst case field. This was compared with the sample test results to give an approximation of the operational safety margin. The highest rield occurrs at the ground (anocie) end of the No. 1 insulalor and is approximately $35 \mathrm{kV} / \mathrm{cm}$ (Fig. 7). This field is approximately a factor of 4 below the flashover stress of the $3.175 \mathrm{~cm}$ sample. The static field distribution across the entire bushing is forced by the electron gun geometry and the presence of metal rings in the stacked-ring Lushing configuration was found to have oll ly a slight effect. 
In conclusion, we have developed a large diameter insulator utilizing epoxy bonding which has sufficient mechanical strength to support the $3000 \mathrm{~kg}$ cathode/grid assembly. Bonding the insulator simplifies the handling and reduces the number of O-ring seals to a minimum. We have described the material selection, bonding rechniques and electrical design approach.

[1] 1.D. Smith, "Pulse breakdown of insulator surfaces in a poor vacuum," Proc, lst Int. Symp. Insulation of High Voltages in Vacuum, F. 261, Oct. 1964.

[2] A. Watson, "Pulsed flashover in vacuum," J. A.ppl. Phys., vol. 38, p. 2019, 1967.

[3] 0. Milton, "Pulsed fiashover of insulators in vacuum," IEEE Transactions on Elect. Insulation, vol. E1-7, No. 1, p. 7-15, March 1972.

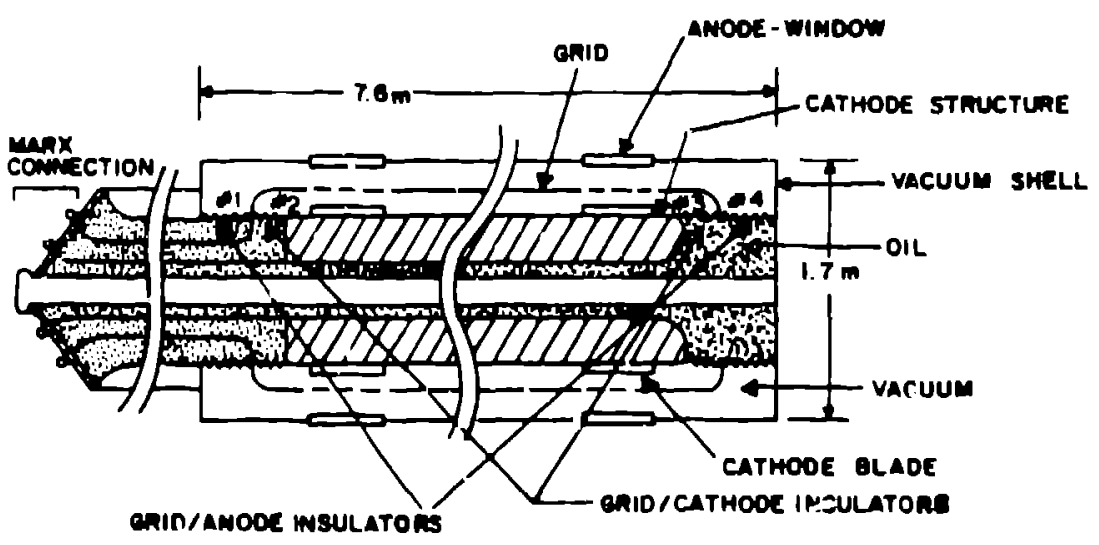

Fig. 1. Antares electron gun configuration. 


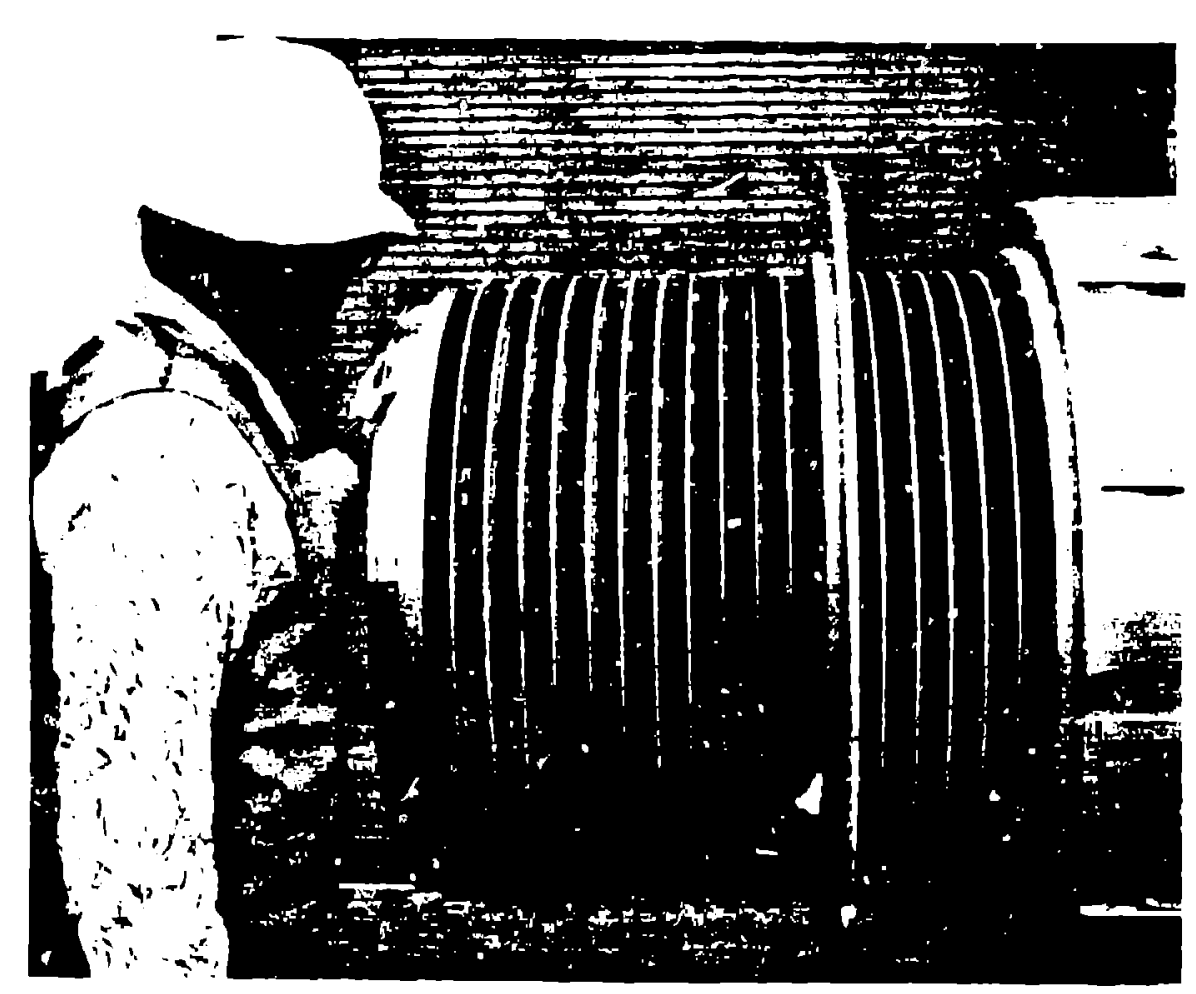

Fig. 2. One end of cathode with grid/anode and grid/ cathode insulators installed. positive ELECTRODE

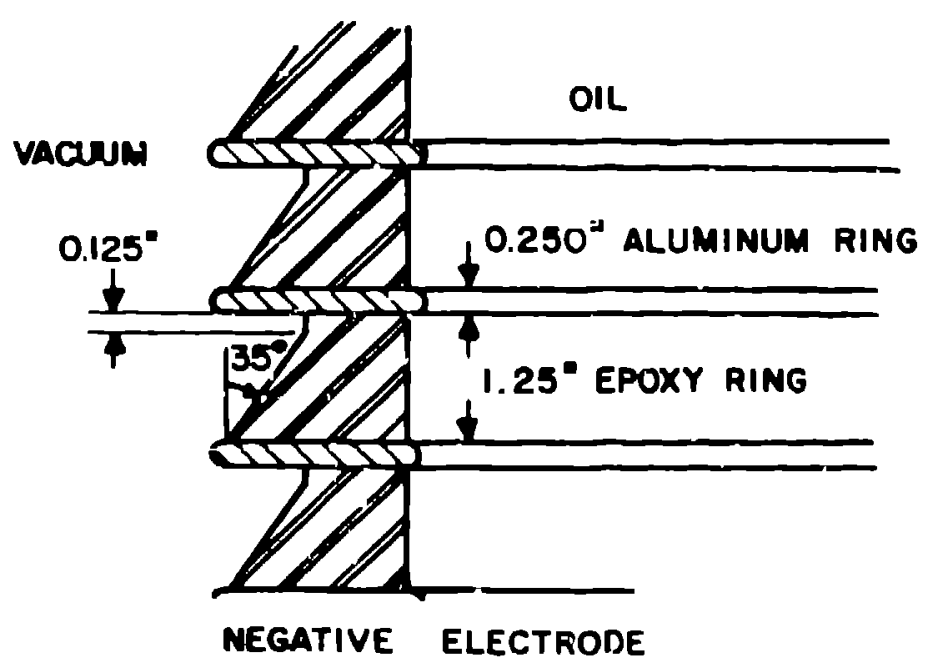

Fig. 3. Insulator construction. 


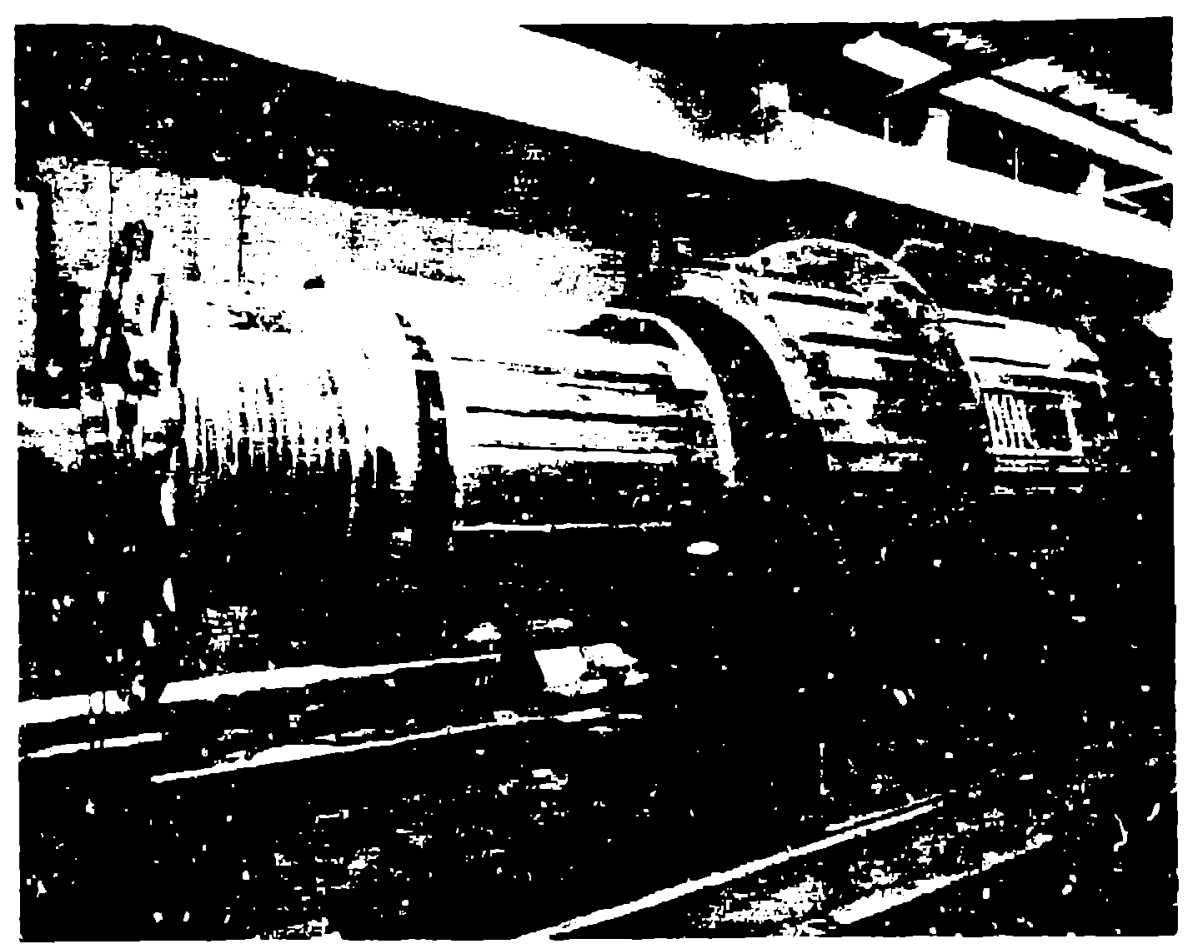

Fig. 4. Grid/cathode assembly, including irsulators being inserted into vacuum shell.

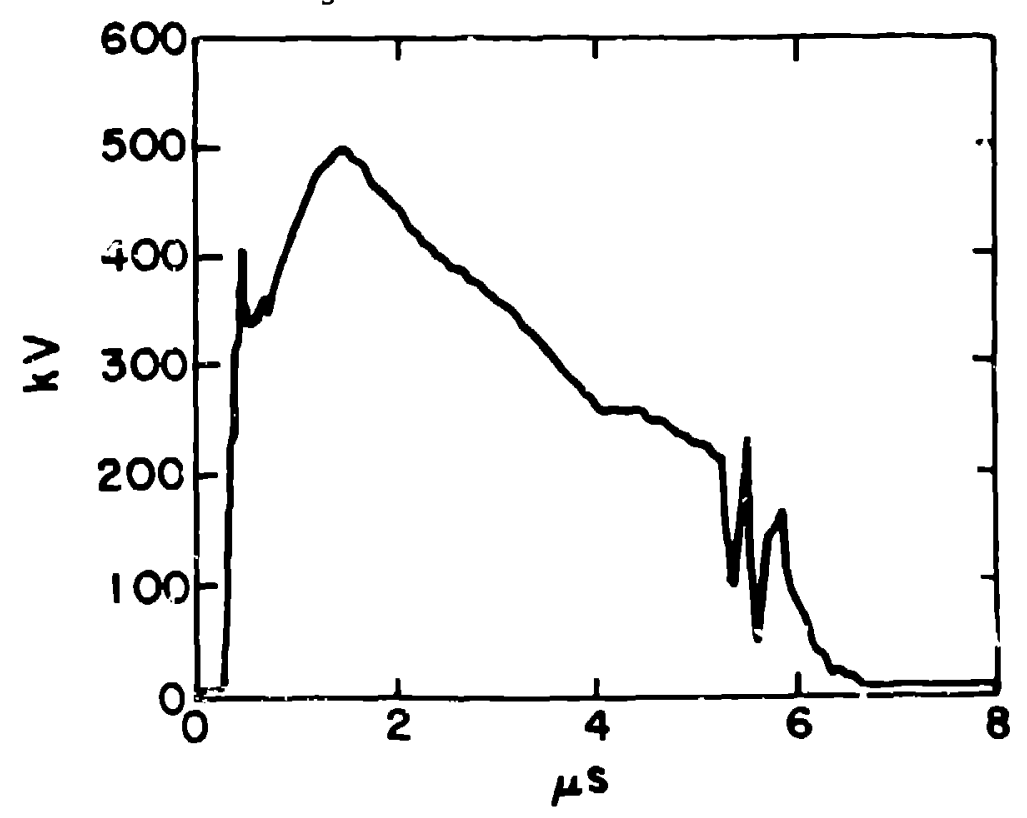

Fig. 5. Cathode voltage wäue shape. 


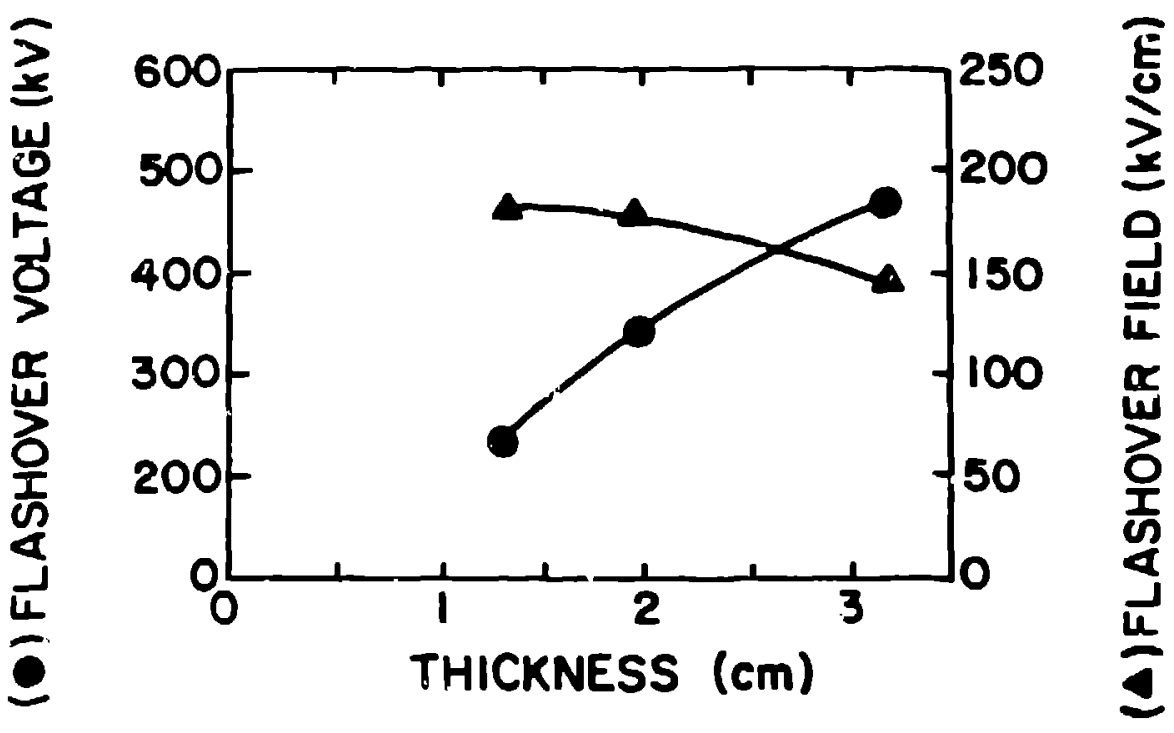

Fig. 6. Flashover voltage and average field for three insulator thicknesses.

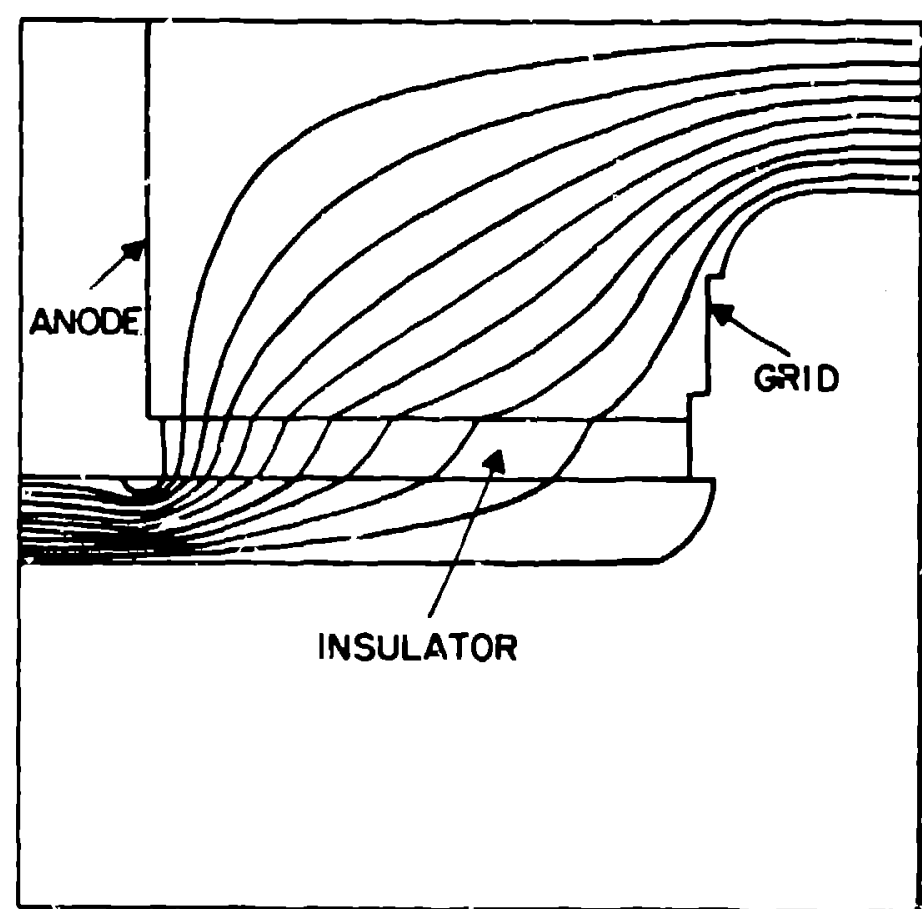

Fig. 7. Typical field plot of highest stress insulator. 